\title{
La investigación pediátrica en Chile y Revista Chilena de Pediatría indexada en Corriente Principal
}

\author{
MARCELA AGUIRRE C. ${ }^{1}$ \\ 1. SciELO Chile, Programa de Información Científica, CONICYT. Santiago, Chile.
}

La Revista Chilena de Pediatría (RCHP) es la revista científica chilena más destacada y antigua en su especialidad, publicada por la Sociedad Chilena de Pediatría desde el año 1931 en forma ininterrumpida y continúa vigente después de 84 años de existencia. A través de sus largos años de publicación ha tenido grandes desafíos por el camino de la gestión editorial, la comunicación de investigaciones y experiencias en pediatría.

RCHP ha sido la fuente confiable de consulta en pediatría en Chile para los profesionales, investigadores, académicos, estudiantes e interesados en la literatura científica de esta rama de la medicina. Sus publicaciones prioritarias son los artículos originales; artículos de revisión; experiencias clínicas; informes de caso (casos clínicos) y otros documentos en temas afines de interés para la comunidad nacional e internacional.

RCHP desde su ingreso e indexación a SciELO Chile en el año 1998 ha acrecentado su flujo de artículos, los manuscritos son sometidos a revisión de pares; asimismo ha elevado su número de consultas, citaciones e impacto, e incorporado modificaciones en su gestión y política editorial acorde al estado del arte en la edición de revistas. Con más de 400 números disponibles en la base de SciELO Chile, y casi 2.000.000 de visitas a los artículos en el período enero-agosto 2014, destaca el continuo esfuerzo por superar barreras editoriales, aumentar flujo de artículos, tener mayor apertura de origen de sus autores, ser más selectiva en la calidad de los artículos que publica, así como su interés por estar representada en los mejores índices internacionales. En este sentido el proceso editoial se ha optimizado para ser aceptada en otras bases de datos e índices de renombre internacional como MEDLINE, Web of Science de Thomson Reuters, entre otros. En este andar finalmente este año 2014 ha sido reconocida y aceptada para ser indexada en la Biblioteca Nacional de Medicina de Estados Unidos conocida internacionalmente por su sigla NLM, que data desde 1836 y se puede decir que es una de las bibliotecas especializadas en literatura biomédica más grande del mundo, siendo altamente consultada año a año por millones de personas. Entre sus bases de datos cabe señalar desde la década de los 60 a MEDLINE, que es la base de datos más importante de la NLM, abarcando los campos de la medicina, enfermería, odontología, veterinaria, salud pública y ciencias básicas. Contiene actualmente más de 22 millones de referencias bibliográficas provenientes de más de 5.000 revistas indexadas desde la década del 60. Pub-

Recibido el 12 de agosto de 2014, aceptado el 20 de agosto de 2014.

Correspondencia a:

Marcela Aguirre C.

E-mail: maguirre@conicyt.cl 
Med por su parte, es un sistema de búsqueda desarrollado por la National Center for Biotechnology Information, NCBI, en la National Library of Medicine. Este motor permite el acceso a Bases de Datos bibliográficas agrupadas por la NLM, como son Medline, Premedline, Genbak y Complete Genoma. Medline además contiene sub-bases (subsets) que pueden ser accedidas directamente desde PubMed, como son PubMed central, BioEthics, AIDS, Cancer, Complementary Medicine, Dental Journals, Nursing Journals, y Core Clinical Journals.

Formar parte de la literatura médica de corriente principal en una de las más exclusivas y renombradas bases de datos del área salud y ciencias biomédicas es un privilegio que ha demandado muchos esfuerzos editoriales al grupo de personas que conforman el equipo editorial de RCHP y que marcará indudablemente un gran hito para la pediatría chilena. $\mathrm{La}$ indexación de la Revista Chilena de Pediatría en Medline/PubMed es un gran desafío para los pediatras, para la Sociedad Chilena de Pediatria, para los investigadores chilenos, y por supuesto para la Revista, que se integrará a la literatura internacional en su especialidad, apertura que inyectará a la Revista otros desafíos mayores, de internacionalización, como la incorporación de más co-editores, aumentar el número de representantes para su Comité Editorial; el aumento de artículos en coautoría, en colaboración con otros países, o autorías internacionales; aumentar flujo de artículos ori- ginales resultantes de proyectos de investigación, que permitirán elevar a la Revista nuevos contenidos investigativos en pediatría y temas afines, lo que con certeza hará subir el número de citas e impacto, elevando su ranking en el contexto internacional de los ranking de revistas de su especialidad. Cabe señalar que esta internacionalización de la Revista significa un gran valor y reconocimiento para los autores y la Revista en general.

Nos parece relevante dar a conocer algunas cifras de los avances de la Revista en el último quinquenio, 2009-2013 demostrando que la curva en cuanto a número de artículos, número de citas recibidas y promedio de artículos por fascículo ha ido en ascenso (fuente SciELO Chile, consultado 12 de agosto de 2014) (figura 1).

Para los datos que se señalan a continuación se ha consultado específicamente la colección SciELO Citation Index en la plataforma WoS de Thomson Reuters. Fecha de consulta, 12 de agosto de 2014. El total de registros indexados y analizados son 374 en el período 2009-2013.

- En tipos de documentos publicados por la naturaleza de la Revista, han predominado los artículos de investigación con un $36,631 \%$; casos clínicos (informes de caso) con un $22,658 \%$ y artículos de revisión con un $10,160 \%$.

- En registros, es decir publicaciones, se da a conocer los países con mayor contribución,

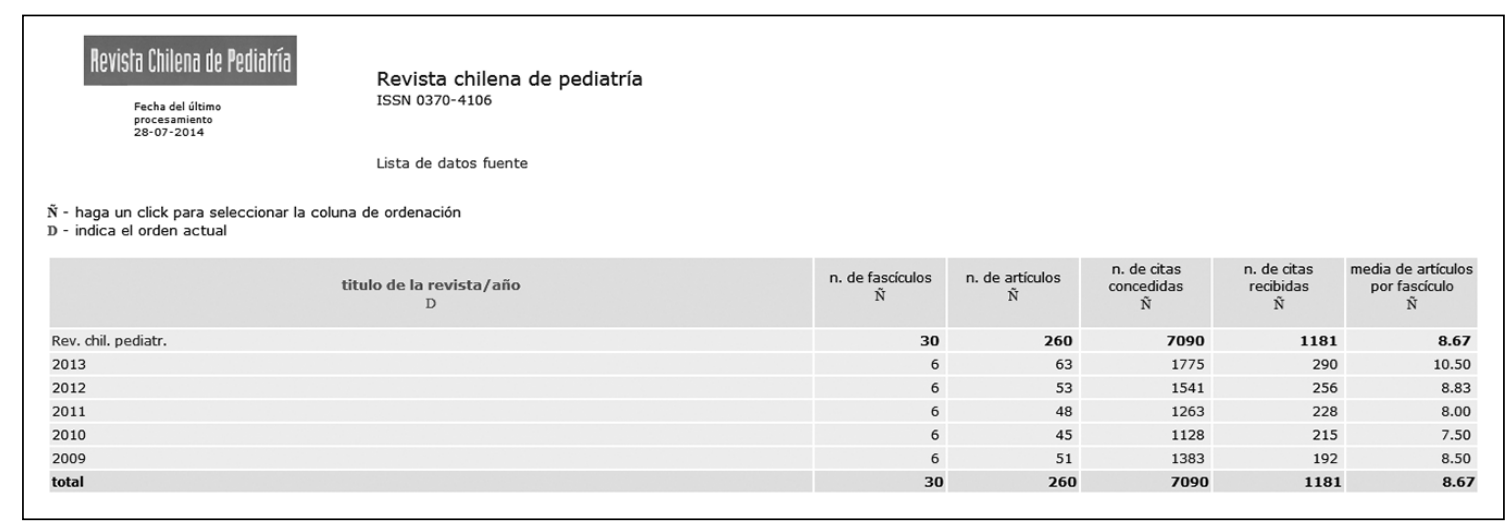

Figura 1. 


\begin{tabular}{|l|c|}
\hline Países & Publicaciones \\
\hline Chile & 276 \\
\hline Colombia & 12 \\
\hline España & 11 \\
\hline Argentina & 7 \\
\hline Venezuela & 5 \\
\hline Brasil & 4 \\
\hline México & 3 \\
\hline Uruguay & 2 \\
\hline Perú & 2 \\
\hline Cuba & 2 \\
\hline Costa Rica & 2 \\
\hline
\end{tabular}

- Estudio de citas. Se da a conocer los resultados relacionados con el total de 374 documentos indexados en SciELO Citation Index.

- Total de veces citada la revista: 95.

- Citas sin contabilizar las citas propias: 67.

- Artículos que han citado la revista: 87.

- Artículos que citan la revista sin las citas propias: 61 .

- Promedio de citas por documento: 0,25.

Según SJR SCImago Journal \& Country Rank, fuente consultada el 12 de agosto de 2014, la Revista Chilena de Pediatría entre los años 2009 y 2013 ha estado posicionada en los siguientes cuartiles; años 2009, 2011, 2012 y
2013 en Q4 (cuartil 4) y el año 2011 subió a Q3 (cuartil 3).

Para concluir, el valor de integrar la literatura de corriente principal, es la posibilidad de expandir universalmente el nuevo conocimiento nacional, los porcentajes en publicaciones de investigaciones originales, casos clínicos y revisiones, conocimientos y experiencias que pasaran a estar indexada y disponibles entre las mejores publicaciones pediátricas, significando también que lo publicado en la Revista Chilena de Pediatría es un aporte al desarrollo y a la sociedad.

Felicitaciones a su Editor Dr. Francisco Cano, Coeditor Dr. Paul Harris, a sus colaboradores y a la Sociedad Chilena de Pediatría que respalda su publicación, por su esforzado y dedicado trabajo a la revista y al logro obtenido ¡ estar indexado en MEDLINE!

\section{Referencias}

1.- NLM. http://www.nlm.nih.gov/. Consultado el 13 de agosto de 2014.

2.- SCImago. (2014). SJR-SCImago Journal \& Country Rank. Retrieved August 13, 2014, from http://www. scimagojr.com 